\title{
Assessment of Awareness of Basic Life Support among Doctors Practising in a Tertiary Care Hospital
}

\author{
Muhammad Zakarya ${ }^{1 *}$, Dr. Khalida Naz Memon ${ }^{2}$, Tasleem Bibi ${ }^{3}$, Bisharat Ali $^{4}$, Erum Aftab Jahangir ${ }^{5}$, Farha Anil ${ }^{6}$, \\ Rahamatullah $^{7}$ \\ ${ }^{1}$ Senior lecturer, Isra University, New Hala - Mirpur Khas Rd Link, Hyderabad, Sindh, Pakistan \\ ${ }^{2}$ Professor, Dean F/O Community Medicine \& Public Health Sceiences, Liaquat University of Medical \& Health Sciences, Jamshoro Sindh, Pakistan \\ ${ }^{3}$ Senior Lecturer, School of Nursing, Liaqaut University Hospital, Hyderabad, Sindh 71000, Pakistan \\ ${ }^{4}$ Nursing Instructor, Isra University, Hyderabad, Sindh, Pakistan \\ ${ }^{5}$ Senior Lecturer, The Rising Star Institute of Nursing, 4 Main Qasimabad Rd, Qasimabad, Hyderabad, Sindh 71000, Pakistan \\ ${ }^{6}$ Director Nursing, St. Elizabeth Hospital Hyderabad, Latifabad Unit 7 Latifabad, Hyderabad, Sindh 71000, Pakistan \\ ${ }^{7}$ Principal, Jamshoro College of Nursing, Jamshoro, Sindh, Pakistan
}

DOI: $10.36348 /$ sjnhc.2020.v03i04.003 $\quad$ Received: 26.03.2020| Accepted: 02.04.2020| Published: 29.04 .2020

*Corresponding author: Muhammad Zakarya

Abstract

Background: The cardiac and respiratory arrest has high mortality rate which can be easily prevented with simple maneuver and skills and CPR which is an effective procedures if adopted under BLS within early critical minutes of cardiac and respiratory arrest. The aim of this study is to determine the level of awareness of basic life support (BLS) among doctors. Methods: Cross-sectional study conducted on doctors working in Liaquat University hospital Hyderabad and Jamshoro. A multi-section questionnaire regarding awareness of Basic Life Support. In total 348 doctors were selected through convenient non-probability sampling technique. Analysis was done in SPSS version 22.0 \& Chi-square test was applied to seek association between variable of interest. Results: The relationship of awareness about BLS to age \& gender of respondents cumulatively showed significant association $(\mathrm{p}=0.01)$. Regarding years of job experience, $60.91 \%$ had experience $2-6$ years; another $11.8 \%$ participants had experience of more than 14 years. Regarding previous experience of BLS, $69 \%$ of respondents replied that they had previous experience of BLS. Around 94.0 respondents were of the opinion that CPR procedure should bemandatory to all health care providers. There were $71.8 \%$ respondents who had complete knowledge about all components of chest compression during CPR. Conclusions: Despite the high level of awareness about BLS among doctors \& enabling environment of hospitals, there is a gap in practicing it. This gap needs to be filled through continuous persuasion of health care providers.

Keywords: Basic life support, cardiac arrested patient, doctors, nurses, cardiopulmonary resuscitation.

Copyright @ 2020: This is an open-access article distributed under the terms of the Creative Commons Attribution license which permits unrestricted use, distribution, and reproduction in any medium for non-commercial use (NonCommercial, or CC-BY-NC) provided the original author and source are credited.

\section{INTRODUCTION}

Saving the life of someone is a responsibility of each and every individual having any role in society; the health care providers are the prime responsible persons for this matter. There are number of persons who experience difficulty in breathing and malfunctioning of cardiac system in numerous ways anytime, anywhere which need to be resolved rapidly, otherwise it creates rapid complications that leads to death. Moreover, various systemic conditions of health like myocardial infarction, congestive cardiac failure, stroke and cessation of breathing leading to even sudden death of an individual. Cardiovascular disease (CVD) is the most common cause of death in developed countries [1]. Cardio respiratory failure is topmost cause of death, accounting for $40 \%$ of all deaths throughout the world [2, 3].

It is reported that in developing countries about 17.3 million people die annually due to CVD [4]. Furthermore, sudden cardiac arrest developing from coronary artery disease (CAD) accounts for $60 \%$ of death and also leading cause of the death; this accounts to 700,000 casualties per anum and usually occurring out of the hospital that leads to death; moreover the survival rate of such cases are very low [5].

In Pakistan more than $50 \%$ of deaths in the adult population are due to cardiovascular diseases and about $30 \%$ of all deaths are due to cardiovascular causes and the highest number of death due to CVD are reported in Pakistan around i.e. half a million and lowest in Qatar i.e. around eight hundred only. There 
are reported 1.4 million in 22 countries of Eastern Mediteranean Region (EMRO) and the most common global causes of CVD related to death is rheumatic heart disease, ischemic heart disease, cerebrovascular diseases, hypertensive disorders, cardiomyopathy and myocarditis, atrial fibrillation and flutter, aortic aneurysm, peripheral vascular disease, and endocarditis [6].

There is a global commitment to reduce premature cardiovascular diseases (CVD) by $25 \%$ by the year 2025, this target is set by United Nations Organization (UNO) for the risk factors of cardiovascular diseases which need to be addressed [7]. The risk factors of CVD must be considered in mind when treating the cardiac disease. Seventy percent of cardiac arrest occurs at out of the hospital (at home) and estimated $50 \%$ percent are unwitnessed and there are only $10 \%$ of adult population patients with nontraumatic cardiac arrest who have been received for emergency treatment and survived to discharg. Moreover, the in-hospital cardiac arrest had better outcome and survival ratio of 22.3 to $25.5 \%$ percent of adult population as compared to outside of the hospitals [8]. There are different ways by which the occurrence of death of an individual may be prevented by keeping the risk factors in the mind. They include the instructions given and medications prescribed by health professionals, diet, and physical exercises. In addition to these ways, basic life support (BLS) in case of medical emergencies is key element for saving a life. The BLS refers to rapid assessment of the patient, establishing and maintaining an airway and supporting breathing and circulation without using any equipment [9]. Moreover, the usage of automated electrical device (AED) is crucial element in survival of the victims of cardiac arrest.

The American Heart Association (AHA) initiated a program named Basic Life Support (BLS) which is the foundation for saving the person's life in response to cardiac and respiratory arrest [10]. It is a mandatory element of training for all health care professionals either working in health care organizations in public sector or private sector or in the community. Moreover, it is basically the assessment of cardiac arrested person, activation of emergency response, early start of cardiopulmonary resuscitation (CPR) and attachment of automated external device (AED). It is the early recognition and early rehabilitation of ventilationas well as circulation. In BLS chest compression and mouth to mouth breathing is given to patient of cardiac arrest. In western world, BLS is supposed to be a prehospital prerequisite for safety of a patient facing cardio respiratory arrest [11]. In developing countries it's a serious concern that not even the common people but the qualified health care providers do not have these skills [12]. Cardiac and respiratory arrest has high mortality rate which can be easily prevented with simple maneuver and skills and
CPR which is an effective procedures if adopted under BLS within early critical minutes of cardiac and respiratory arrest [13]. Doctors are important team member of health care professionals who are expected to perform key role in the basic skills and attitude towards the restoration in the function of cardiac and respiratory arrest patient because they always perform the role of a team leader in the resuscitations. Therefore their knowledge and decision making skills matter in the saving the patient's life because of time, and time matters in this condition. Delay in any decisions in starting the basic steps of CPR will affect victims condition and cause complication or even death of the patient. Unfortunately, the health care providers including doctors, nurses and paramedical staff in our set up are less aware about these life saving techniques of BLS.

Though being a real important issue, there is still too less attention given to this aspect of training to health care providers in our set up. In recent years, several publications have highlighted the deficiencies in CPR quality, both out-of-hospital and in-hospital. This highlights a wide gap of research on this aspect of medical profession and iclusion of BLS training in medical curriculum.

\section{METHODS \\ OBJECTIVES}

1. To identify the level of the awareness of Basic Life Support (BLS) among doctors.

2. To assess determinants of lack of awareness of BLS among study subjects.

\section{Study Setting}

All the medical allied and surgical allied wards at Liaquat University of Medical and Health Sciences Jamshoro/Hyderabad in Sindh province of Pakistan which is a tertiary care hospital comprising of fifty two wards.

Study Design: Cross-sectional study.

Sampling Technique: Non probability convenience sampling.

\section{Sample Size}

The sample size was separately calculated for doctors as under:

$$
\mathrm{n}=\mathrm{z}^{2} \times \mathrm{pxq}
$$

Where

$$
\begin{aligned}
& \mathrm{n}=\text { sample size } \\
& \mathrm{z}=\text { critical value at } 95 \% \text { confidence interval }= \\
& 1.96 \\
& \mathrm{p}=\text { prevalence of doctors using BLS } \\
& \mathrm{q}=100-\mathrm{p} \\
& \mathrm{e}=\text { margin of error }
\end{aligned}
$$




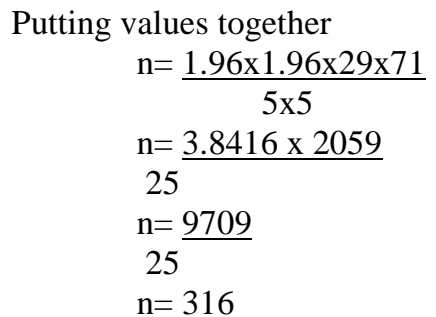

Adding $10 \%$ non-responders, the sample size was 348 .

\section{Inclusion Criteria}

All doctors of both genders working on fulltime basis in designated hospital, giving consent to be the part of research were enrolled as research participants.

\section{Exclusion Criteria}

In order to get valid results, all those doctors who refused to give written informed consent or who were working as part time care providers or on contract basis, were excluded from study.

\section{Variables}

A. Demographic Variables
1. Age
2. Gender
3. Years of experience
4. Awareness about BLS

B. Variables of Special Interest

1. Previous experience of BLS

2. Resource availability status.

3. Reasons of lack of knowledge about BLS.

\section{Data Collection Tool}

The data was collected on a pre-formed questionnaire tool designed by principle researcher and partially adopted by Meena Kumari et al form their research on the topic of "Clinical Awareness of Do's and Don'ts of Cardiopulmonary Resuscitation (CPR) Among University Medical Students-A Questionnaire Study". The questionnaire consisted of total twenty seven items arranged in four sections related to the socio-demographic data of the respondents, their awareness and attitude towards basic life support. The data was collected on a Likert scale. The cumulative expected score by the subjects varied between 0 to 27 .
The response scores were divided into three categories as under:

$$
\begin{aligned}
& 0-09=\text { Inadequate knowledge } \\
& 10-18=\text { Some knowledge } \\
& >18=\text { Highest knowledge }
\end{aligned}
$$

Piloting of research was done on 25 subjects and alpha Cronbach reliability index was computed as 0.72 .

\section{Data Collection Method}

Data was collected after approval from Research Ethics Committee (REC), of Liaquat University of Medical and Health Sciences Jamshoro. The participants were enrolled after obtaining written consent.

\section{Data Analysis plan}

The data was compiled and analyzed through Statistical Package for Social Sciences (SPSS) for window (SPSS) version 22.0. For categorical variables e.g. designation, previous experience of BLS and awareness about BLS etc. frequencies and percentages were calculated along with their graphical presentations.. For continuous variables e.g., age and years of experience etc., mean \pm standard deviations were used as summary measures. Chi-square test was applied for categorical variables and the level of significance was set at p-value $\leq 0.05$ at $95 \%$ confidence interval.

\section{RESULTS}

The age distribution of respondents was 33.90 \pm 7.01 years. There was female preponderance among study participants i.e. $63.50 \%$ females as compared to $36.50 \%$ males. The relationship of awareness about BLS \& these two variables cumulatively showed significant association $(\mathrm{p}=0.01)$. Regarding years of job experience, $60.91 \%$ had experience $2-6$ years; another $11.8 \%$ participants had experience of more than 14 years. Regarding previous experience of BLS, $69 \%$ of respondents replied that they had previous experience of BLS; but when explored about training status in past two years, there were only $30 \%$ who declared that they had such training in previous two years.

Chart-1 depicts the level of awareness about importance of BLS among study participants. 


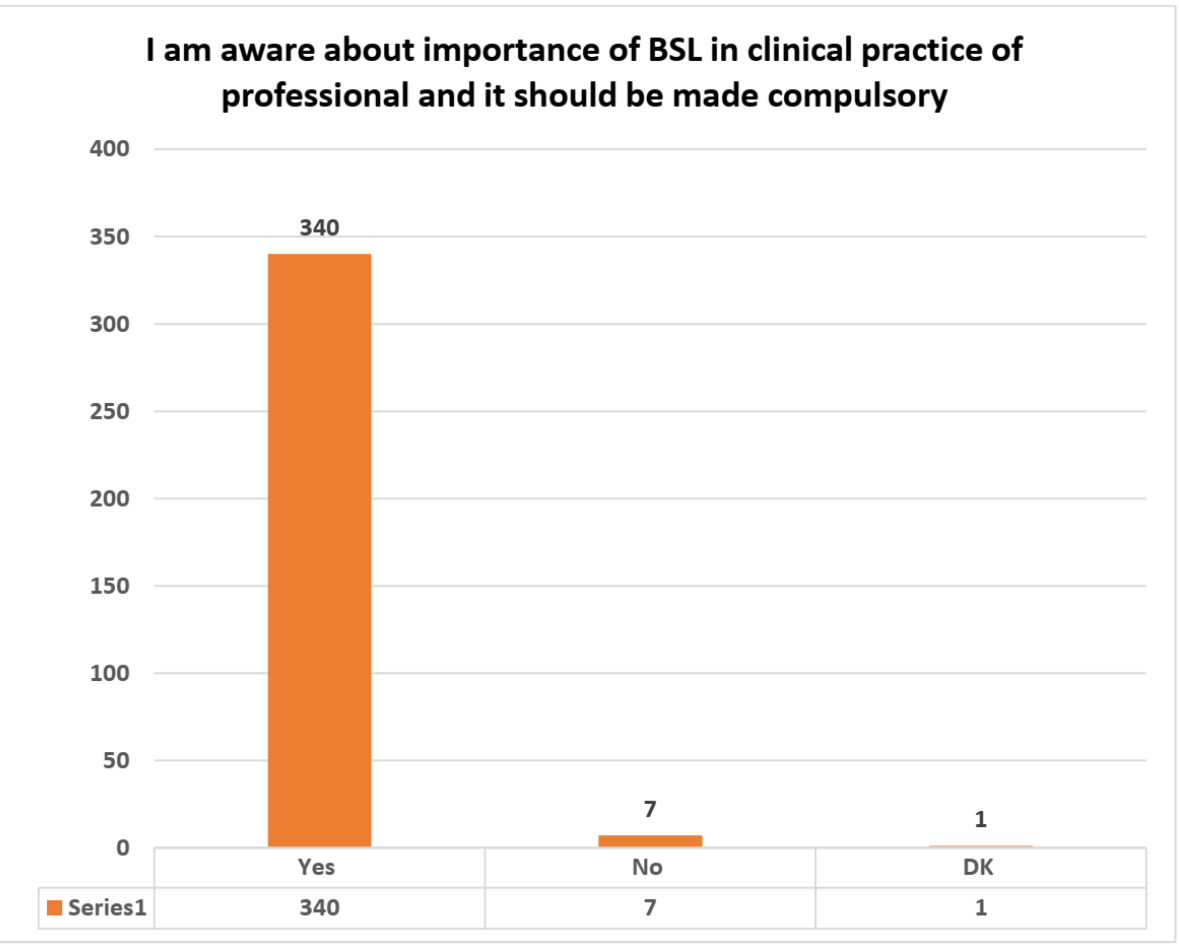

Chart-1: Awareness Regarding Importance of BLS among Study Participants

When asked whether knowledge of correct CPR procedure is mandatory to all health care providers, $94.0 \%$ respondents replied in affirmation.

Table-1: Awareness Regarding Basic Life Support Among Study Participants

\begin{tabular}{|c|c|c|c|c|c|}
\hline S. No & Criteria of Awareness & Doctors & & & \\
\hline \multirow[t]{2}{*}{01} & \multirow[t]{2}{*}{$\begin{array}{l}\text { I am aware about importance of CPR in clinical practice } \\
\text { professionals and it should be made compulsory. }\end{array}$} & Yes & No & $\begin{array}{ll}\text { Do not } \\
\text { know }\end{array}$ & \multirow[t]{2}{*}{$<0.01$} \\
\hline & & $\begin{array}{l}340 \\
(97.7 \%)\end{array}$ & $\begin{array}{l}5 \\
(1.4 \%)\end{array}$ & $\begin{array}{l}3 \\
(0.9)\end{array}$ & \\
\hline 02 & $\begin{array}{l}\text { CPR is an emergency procedure which is attempted in an } \\
\text { effort to return life in cardiac arrest. }\end{array}$ & $\begin{array}{l}340 \\
(97.7 \%)\end{array}$ & $\begin{array}{l}7 \\
(2.0 \%)\end{array}$ & $\begin{array}{l}1 \\
(0.3 \%)\end{array}$ & $<0.01$ \\
\hline \multirow[t]{2}{*}{03} & \multirow{2}{*}{$\begin{array}{l}\text { It has to be attempted always inside the hospital not } \\
\text { outside. }\end{array}$} & Yes & No & DK & \multirow[t]{2}{*}{$<0.01$} \\
\hline & & $\begin{array}{l}148 \\
(42.5 \%)\end{array}$ & $\begin{array}{l}195 \\
(56.0 \%)\end{array}$ & $\begin{array}{l}5 \\
(1.4 \%)\end{array}$ & \\
\hline
\end{tabular}

Regarding to query related to critique of I am aware about importance of CPR in clinical practice professionals and it should be made compulsory, $97.7 \%$ doctors said yes in contrast to $76.7 \%$ nurses replied as 'yes' $(p<0.01)$ and related to CPR is an emergency procedure which is attempted in an effort to return life in cardiac arrest, $97.7 \%$ doctors verbalized yes while $73.1 \%$ nurses said Yes to this option ( $\mathrm{p}<0.01$ ). Moreover, related to critique of 'It has to be attempted always inside of a hospital not outside $42.5 \%$ doctors said 'Yes' in compare to $59.6 \%$ nurses verbalized yes to that question and $\mathrm{p}$ value is less than $(\mathrm{p}<0.01)$

Table-2: Knowledge Of Study Participants Regarding Recommended Procedures For Chest Compression

\begin{tabular}{|l|l|}
\hline Options & Frequency (\%) \\
\hline Depth of adults and children is about 5 cm (2 inches) & $44(12.6 \%)$ \\
\hline In infant it is 4 cm (1.5 inches) & $10(2.9 \%)$ \\
\hline In adult, rescuer should use two hands for the chest compression & $27(7.8 \%)$ \\
\hline In children they should use one hnads & $4(1.1 \%)$ \\
\hline With infants two fingers (index and middle fingers) & $13(3.7 \%)$ \\
\hline All of the above & $250(71.8 \%)$ \\
\hline
\end{tabular}




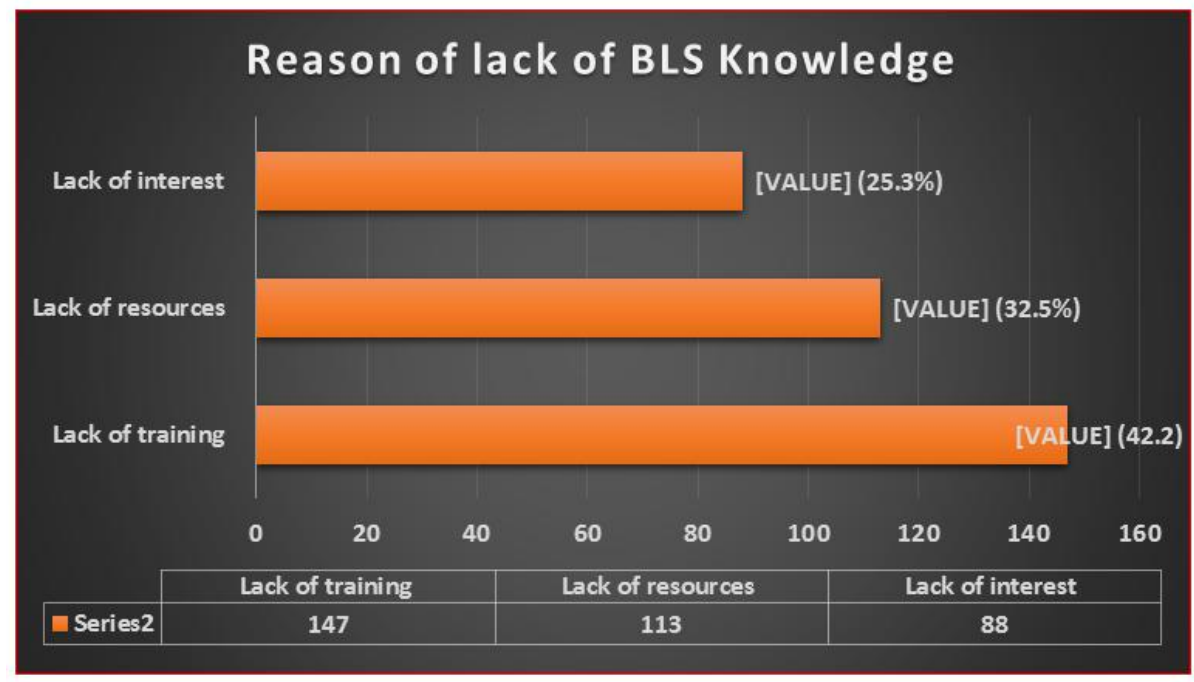

Chart-2: Reasons of lack of BLS Knowledge Among study Participants

\section{DISCUSSION}

This study was conducted to identify the awareness regarding basic life support among doctors working in tertiary care hospital. The study was conducted on a total sample of three hundred forty eight (348) participant.

The result of study shows that majority of participant $43.4 \%$ were in the 25-30 years of age, with mean age of $33.9 \pm 7.01$ years. Another study conduted in Pakistan with the similar objectives concluded that $81.4 \%$ doctors having age of 23-25 years [14]. Similarly there was a research on the same subject conducted in Karachi, Pakistan which revealed this figure as $88.8 \%$ among doctors having 20-29 years of age [15], but these studies did not report significant difference. These mean differences could be because of the researcher's inclusion of different age groups in study.

Regarding the already experience of BLS, the participant showed that $69.0 \%$ had already experience of BLS and as same finding comes from an other study which was conducted at Karachi, Pakistan which shows that $67.4 \%$ doctors had already trained for BLS [16], incontinuation to that an other study while an other study shows that $47.1 \%$ had already experience of BLS [17].

As far as CPR awareness was concerned the current study findings suggest that $94.5 \%$ research participants were aware of the importance of CPR.

As far as concerned for the current order of updated cardiopulmonary resustitation, $41.3 \%$ participant had chest compressions, Airway, Breathing $(\mathrm{CAB})$ in the study. Another researchwhich is conducted in India showed $84.5 \%$ of the doctors as having correct knowledge of the recommended sequence of CPR related activities [18].
As for as concern of recommended universal compression to ventilation ratio with compression rate of at least 100 per minutes in all age groups is, $78.0 \%$ replied that 30:2 for adults, children and infant if only a single rescuer is present. Another study was conducted at Karachi that shows that $53.0 \%$ doctors had correct correct compression to ventilation ratio that is $30: 2$ [14]. Another study conducted in India showed that $84.9 \%$ doctors had correct knowledge of chestcompression: ventilation ratio and regarding rate of chest compression showed $35.6 \%$ of the doctors having correct knowledge of rate of chest compression 18]. An other study which is conducted on doctors that shows that $28.2 \%$ participant knew about the chest compression ventilation ratio that $30: 2$ correctly [11].

As for as concern for depth of chest compression the currect study shows that $67.8 \%$ narrated as 'Yes'. Another comparative study showed that $43.2 \%$ participant verbalized that chest compressions be at atleast 100 per minutes [14]. Another study conducted in Rawalpindi-Islamabad, Pakistan showed that $26.7 \%$ research participant were aware of rate and depth of chest compression and chest compression to ventilation ratio in different age groups [11]. A hospital-based research in Karachi, Pakistan showed that only $14.2 \%$ research participant had correct knowledge of chest compression depth [14]. In comparison to it, an Indian research reported that $29.7 \%$ research participant had correct knowledge about the depth of chest compression 19].

Concerning the query about the association between survival rate and time of initiation of CPR, $71 \%$ respondents were of the opinion that the survival rate would be high if immediate CPR is done followed by defibrillation within 3-5 minutes of sudden cardiac arrest" doctors replied yes as $71 \%$. This finding is quite comparable with two other studies' results revealing aroud $70-72 \%$ doctors confirming the same views [20, 21]. 
As far as concerned ror the reasons of lack of awareness of BLS, $42.2 \%$ research participant had verbalized that lack of training, $32.5 \%$ had said that lack of resources, and $25.3 \%$ had said that they had lack of interest. Another study which is conducted in Karachi, Pakistan on doctors and nurses that reaearch participant shows lack of proper knowledge is because of limited number of trainings and unavailability of resources were the reason of not having adequate awaresess of BLS [17]. As in currect study majority of the research participant verbalized that they have a need of BLS trainings, same finding were highlighted the possible short of BLS tainings and these will be addressed soon for increasing awarenees of BLS and the survey also found poor knowledge in the sample population, as well as poor access to training [22]. These findings were endorsed by another research showing lack of proper awareness of CPR as attributed to busy schedule, lack of training and lack of resources available [19].

\section{CONCLUSIONS}

The study was conducted on a total sample of 348 doctorss revealed majority of participant $43.0 \%$ were in the 25-30 years of age, with mean age of 33.57 \pm 6.672 years. Arround $64.0 \%$ were having $2-5$ years of experience. Only $27.5 \%$ had received the BLS training. Encouragingly, $94.5 \%$ research participant were aware of importance of cardio pulmonary resuscitation. The study showed that more than $80 \%$ doctors answered correct about defibrillator.

\section{All authors hereby declare that}

- There is no conflict of interes; the manuscript has been read by all authors.

- The submitted manuscript is not a result of funded research.

\section{ACKNOWLEDGEMENT}

I should acknowledge to the Meena Kumari and Mohan Babu Amberkar and their research team for allowing me to use the research quaestionnarie. I am very thankfull to Madam Rubecca Wilson John and Dr. Ambreen Sehito for their continuous help and support

\section{REFERENCES}

1. Piepoli, M. F., Hoes, A. W., Agewall, S., Albus, C., Brotons, C., Catapano, A. L., ... Gale, C. (2016). 2016 European Guidelines on cardiovascular disease prevention in clinical practice. European Heart Journal.

2. Mensah, G. A., Roth, G. A., Sampson, U. K., Moran, A. E., Feigin, V. L., Forouzanfar, M. H., ... Murray, C. J. (2015). Cardiovascular Topics Mortality from cardiovascular diseases in subSaharan africa, 1990-2013: a systematic analysis of data from the Global Burden of disease Study, 2013, 26(2).

3. CPSP. (n.d.). :::College of Physicians and
Surgeons Pakistan. Retrieved February 27, 2018, from https://www.cpsp.edu.pk/bls-program.php

4. Gaziano, T. A., Bitton, A., Anand, S., AbrahamsGessel, S., \& Murphy, A. (n.d.). Growing Epidemic of Coronary Heart Disease in Low-and Middle- Income Countries. https://doi.org/10.1016/j.cpcardiol.2009.10.002

5. Anargiroi, A. (n.d.). Factors that influence nursing staff attitudes towards initiating CPR and in using an automatic external defibrillator when outside of a hospital, 88-101.

6. Mokdad, A. H. (n.d.). Burden of cardiovascular diseases in the Eastern Mediterranean Region, 1990-2015: findings from the Global Burden of Disease 2015 study GBD 2015 Eastern Mediterranean Region Cardiovascular Disease Collaborators@BULLET.

7. Sacco, R. L., Roth, G. A., Reddy, K. S., Arnett, D. K., Bonita, R., Gaziano, T. A., ... Zoghbi, W. A. (2016). The Heart of 25 by 25: Achieving the Goal of Reducing Global and Regional Premature Deaths From Cardiovascular Diseases and Stroke: A Modeling Study From the American Heart Association and World Heart Federation. Circulation, 133(23), e674-e690.

8. Rajashekar, S., M. R., N. G., \& Anthony, A. (2018). Knowledge of basic life support among health care professionals in a tertiary care hospital in Chitradurga. International Journal Of Community Medicine And Public Health, 5(9):3969.

9. Santos, S. V., Margarido, M. R. R. A., Caires, I. S., Santos, R. A. N., Souza, S. G., Souza, J. M. A., ... Pazin-Filho, A. (2015). Basic life support knowledge of first-year university students from Brazil. Brazilian Journal of Medical and Biological Research, 48(12):1151-1155.

10. Berg, R. A., Hemphill, R., Abella, B. S., Aufderheide, T. P., Cave, D. M., Hazinski, M. F., ... Swor, R. A. (2010). Part 5: Adult basic life support: 2010 American Heart Association Guidelines for Cardiopulmonary Resuscitation and Emergency Cardiovascular Care. Circulation, 122(SUPPL. 3).

11. Zamir, Q., Nadeem, A., \& Rizvi, A. H. (2012). Awareness of cardiopulmonary resuscitation in medical-students and doctors in RawalpindiIslamabad, Pakistan. Journal of the Pakistan Medical Association, 62(12), 1361-1364.

12. Sabir, M. (2017). Identify Knowledge of Basic Cardiac Life Support among Nursing Student. International Journal of Scientific and Research Publications, 7(6). Retrieved from www.ijsrp.org

13. Zaheer, H., \& Haque, Z. (2009). Awareness about BLS (CPR) among medical students: Status and requirements. Journal of the Pakistan Medical Association, 59(1):57-59.

14. Ghauri, S. K., Javaeed, A., Shah, F., \& Ghani, M. U. H. (2019). Dismal situation of cardio pulmonary resuscitation knowledge and skills 
among junior doctors in twin cities of Pakistan. Pakistan Journal of Medical Sciences, 35(5):1295-1300.

15. Majid, A., Jamali, M., Ashrafi, M. M., Ul Haq, Z., Irfan, R., Rehan, A., ... Menezes, R. G. (2019). Knowledge and Attitude Towards Cardiopulmonary Resuscitation Among Doctors of a Tertiary Care Hospital in Karachi. Cureus, 11(3).

16. Rubeen, R., Zareen, N., Khan, F., Rattan, S., Mo1z, M., \& Nousheen, N. (2013). Awareness and Practice of Basic Life Support Among Doctors in Civil Hospital Karachi. Medical Channel, 19(1), 15-18. Retrieved from https://libproxy.library.unt.edu:9443/login?url=htt p://search.ebscohost.com/login.aspx?direct=true \& $\mathrm{db}=\mathrm{a} 9 \mathrm{~h} \& \mathrm{AN}=100344961 \&$ site $=$ ehost -

live \&scope $=$ site

17. Irfan, B., Zahid, I., Khan, M. S., Khan, O. A. A., Zaidi, S., Awan, S., ... Irfan, O. (2019). Current state of knowledge of basic life support in health professionals of the largest city in Pakistan: a cross-sectional study. BMC Health Services Research, 19(1):865.

18. Chaudhari, M. S., Panchal, N. N., Kamat, H. V., \& Ganjiwale, J. (2017). Knowledge of 2015 basic life support (BLS) guidelines among doctors and nursing staff of a rural based tertiary care hospital, in western India: Current status and requirement. Indian Journal of Clinical Anaesthesia, 4(2):193197.

19. Roshana, S., Kh, B., Rm, P., \& Mw, S. (2012). Basic life support: knowledge and attitude of medical/paramedical professionals. World Journal of Emergency Medicine, 3(2):141-145.

20. Vural, M., Koşar, M. F., Kerimoğlu, O., Kızkapan, F., Kahyaoğlu, S., Tuğrul, S., \& İşleyen, H. B. (2017). Cardiopulmonary resuscitation knowledge among nursing students:A questionnaire study. Anatolian Journal of Cardiology, 17(2), 140-145.

21. Meena Kumari, K., Amberkar, M. B., Alur, S. S., Bhat, P. M., \& Bansal, S. (2014). Clinical awareness of do's and don'ts of cardiopulmonary resuscitation among university medical students-A questionnaire study. Journal of Clinical and Diagnostic Research, 8(7):1-4.

22. Keenan, M., Lamacraft, G., \& Joubert, G. (2009). A survey of nurses' basic life support knowledge and training at a tertiary hospital. African Journal of Health Professions Education, 1(1), 3-7. 